\title{
Visual Resolution and Optical Scintillation in Stable Stratification over Snow ${ }^{1,2}$
}

\author{
EDWARd RyzNaR \\ The Universily of Michigan \\ (Manuscript received 9 November 1962)
}

\begin{abstract}
The effects of turbulent fluctuations of atmospheric density are seen as rapid changes in the brightness of a distant light source (scintillation) and in the position and size of distant objects (shimmer). The results of an investigation of the effects in a horizontal optical path $543 \mathrm{~m}$ long and $1.5 \mathrm{~m}$ high over a uniform snow surface are described.

It was found that deterioration in visual resolution caused by shimmer was most pronounced when the atmosphere was clear, a time when the detection and recogmition of distant objects were otherwise unimpeded. Visual resolution deteriorated and scintillation intensity increased systematically with increasing inversion magnitude in turbulent flow. Resolution was best in windy and cloudy conditions and poorest on clear nights with light wind speeds.
\end{abstract}

\section{Introduction}

Visual detection and recognition of distant objects are critically dependent on atmospheric conditions in the line of sight. If there are diffraction and refraction effects caused by turbulent fluctuations of atmospheric density, an observer viewing a distant object sees rapid changes in its brightness (or intensity), color, position, and size. Brightness and color fluctuations are referred to as brightness scintillation and color scintillation, respectively (Ellison, 1954). The distortion and associated image motion are often referred to as shimmer or "boil" (Middleton, 1952). The net effects are to blur the object and thereby to reduce the apparent contrast between the object and its background (Duntley et al., $\left.{ }^{3}\right)$. In this way, an individual's visual resolution, defined as his ability to discern the object's fine detail, or more precisely, as his ability to resolve spatial separation of two portions of his visual field, is deleteriously affected. Shimmer effects are most pronounced in clear weather when visual resolution would otherwise be optimum. They act, therefore, as the limiting factors in the ultimate resolution obtainable with optical devices for distant viewing. As a result, work in astronomy, geodesy, and military surveillance is often seriously handicapped by scintillation and shimmer effects. Com-

\footnotetext{
1 Publication No. 78 of the Meteorological Laboratories, University of Michigan.

2 Research of shimmer effects on visual resolution supported by the U. S. Army Cold Regions Research and Engineering Laboratory (contract DA-11-190-ENG-78) and conducted concurrently with a study of optical effects of atmospheric turbulence supported by the National Science Foundation (Grant 16016). Presented at the 203rd National Meeting of the American Meteorological Society, Fairbanks, Alaska, 26-28 June 1962.

${ }^{3}$ Duntley, S. Q., W. H. Culver, F. Richey and R. W. Preisendorfer, 1958: The reduction of contrasi by almospheric boil. Univ. of Calif., Scripps Inst. of Ocean. Vis. Lab., 19 pp. (AD 268 121).
}

munications methods which utilize light propagation are also similarly affected.

\section{Purpose and plan of the investigation}

The atmospheric density fluctuations responsible for both scintillation and the impairment of visual resolution due to shimmer are the result of incomplete turbulent mixing of thermally stratified layers. To investigate these phenomena, optical scintillation, visual resolution, and wind and temperature profiles were measured simultaneously in the same horizontal optical path. The information obtained enabled studies to be made of (1) the intensity and frequency characteristics of optical scintillation in relation to atmospheric turbulence and (2) resolution conditions in such a way as to contribute to their predictability for various meteorological conditions.

Studies (1) and (2) supplement each other because scintillation and shimmer appear to be closely related. In study (1), some results of which were reported by Portman et al., (1962), measurements of scintillation were related to temperature profiles, wind speeds, Richardson numbers, and path lengths. Power spectra of scintillation frequency under various conditions of stably stratified flow were also discussed. In study (2), which is the main topic of the following discussion, it was reasoned that if empirical relationships could be established between visual resolution and micrometeorological parameters such as wind velocity and vertical temperature gradient, it would then be possible to predict resolution conditions from standard meteorological and surface information. The compatibility of the two studies is illustrated in the present article by an empirical relationship of visual resolution to scintillation. 
As part of the investigation, field experiments were conducted over a grass surface in 1958 (Bellaire and Elder, ${ }^{4}$ ) and 1959 (Bellaire and Ryznar, ${ }^{5}$ ). These works discuss general relationships between scintillation and micrometeorological parameters and present initial findings of the effects of shimmer on visual resolution. The present article is based on field experiments with improved scintillation and resolution equipment conducted over a level snow field about $0.5 \mathrm{~m}$ deep at the U. S. Army Cold Regions Research and Engineering Laboratory's Keweenaw Field Station, Houghton, Mich., in February and March, 1960. The field experiments and some analysis results are described by Portman et al. ${ }^{6}$ The following discussion utilizes information obtained in these investigations to relate visual resolution to standard weather station observations.

\section{Equipment and procedures}

Optical scintillation measurements. The intensity of apparent brightness fluctuations of a D.C. light source about $1.5 \mathrm{~m}$ above snow was measured by a telephotometer at the same height $543 \mathrm{~m}$ away. The fluctuations were measured in terms of the per cent modulation of the received signal, defined as the ratio of the mean peak to peak amplitude of an A.C. component of the signal to the average, or D.C. level. This quantity, abbreviated as $\mathrm{Pm}$, gave a measure of the intensity of fluctuations independent of slow changes in brightness due to attenuation by the atmosphere. The method of scintillation measurement is described in greater detail by Portman, et al. ${ }^{7}$ Similar measurements of scintillation were made by Siedentopf and Wisshak (1948), Tatarski et al., (1958), and Gurvich, Tatarski and Cvang (1958).

Meteorological measurements. Wind and temperature profiles and wind direction were measured continuously throughout all periods of scintillation measurement. The profiles were measured with sensors at nominal heights of $0.5,1.0,2.0$ and $4.0 \mathrm{~m}$ above snow. Wind speed was measured with Beckman and Whitley Model 170-34 anemometers. Temperature was measured with No. $36 \mathrm{~B}$ and S gauge copper-constantan thermocouple junctions supported in flat-plate radiation shields. In addition, standard weather observations were available from the U.S. Weather Bureau station adjacent to the field experiment site at the Houghton County Airport.

\footnotetext{
${ }^{4}$ Bellaire, F. R., and F. C. Elder, 1960: Scintillation and visual resolution over the ground. Univ. of Mich. Willow Run Labs. Rep. No. 2900-234-T, 46 pp. (OTS PB 152682 ).

${ }^{5}$ Bellaire, F. R., and E. Ryznar, 1961 : Scintillation and visual resolution over the ground. Univ. of Mich. Inst. of Sci. and Tech. Rep. No. 2900-293-T, 28 pp. (AD 267 088).

6 Portman, D. J., E. Ryznar, F. C. Elder and V. E. Noble, 1961 : $V$ isual resolution and optical scintillation over snow, ice, and frozen ground. Univ. of Michigan Office of Res. Admin. Report No. 03372-17-P, Sept., 1961, 123 pp. (U. S. Army Cold Regions Res. and Eng. Lab. Res. Report No. 111 in print).

${ }^{7}$ Portman, D. J., E. Ryznar, F. C. Elder and V. E. Noble, op cit.
}

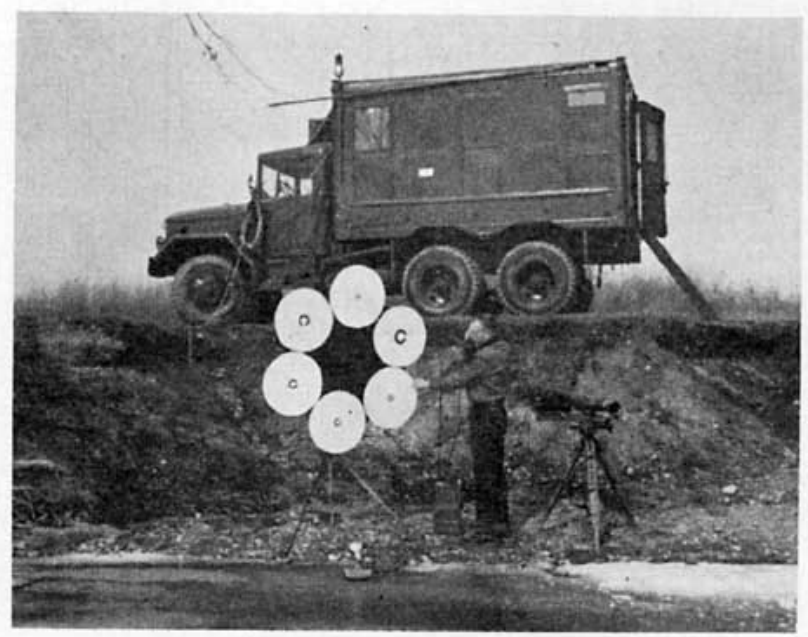

FIG. 1. Landolt broken-ring chart, telephotometer, and communications system.

Visual resolution determination. A Landolt brokenring resolution chart was used to determine an observer's visual resolution capabilities. Fig. 1 shows the chart as it appeared during measurements over ice. The visual targets were black broken rings (C-shaped figures) photographically reproduced and dry-mounted on 20-inch white cardboard disks. The brightness contrast, defined as the ratio of the brightness difference between the white background and the black ring to the brightness of the background, was 0.96. At any one time six disks with rings of different sizes were attached peripherally to the larger main disk that could be rotated to permit any ring to appear in the viewing position at the optical path height of $1.5 \mathrm{~m}$. Once in the viewing position, each broken ring could also be rotated to any desired orientation. For nighttime operation, the chart was uniformly illuminated by flood lights.

Twenty-one broken rings with outside diameters from 0.20 to 17.76 inches were available. The slot size of each ring was the length of a side of the approximately square gap. It equaled the ring thickness and ranged from 0.04 to 3.55 inches for the various rings. Each broken ring was 1.25 times larger than the next smallest one in the series. The ratio 1.25 , selected on the basis of experimental results obtained by Fritz (1928), was used by Gordon ${ }^{8}$ in tests to evaluate the optical design of night binoculars.

The resolution chart was located near the telephotometer and operated by a person in telephone communication with an observer stationed near the light source. The observer, shown in Fig. 2, viewed the chart with a 24-power telescope and reported his estimate of the orientation of each broken ring brought into viewing position by the chart operator. Progressively smaller

\footnotetext{
${ }^{8}$ Gordon, D. A., 1959: The optical design of night binoculars. Univ. of Mich. Willow Run Labs., Unpbl. Rep.
} 


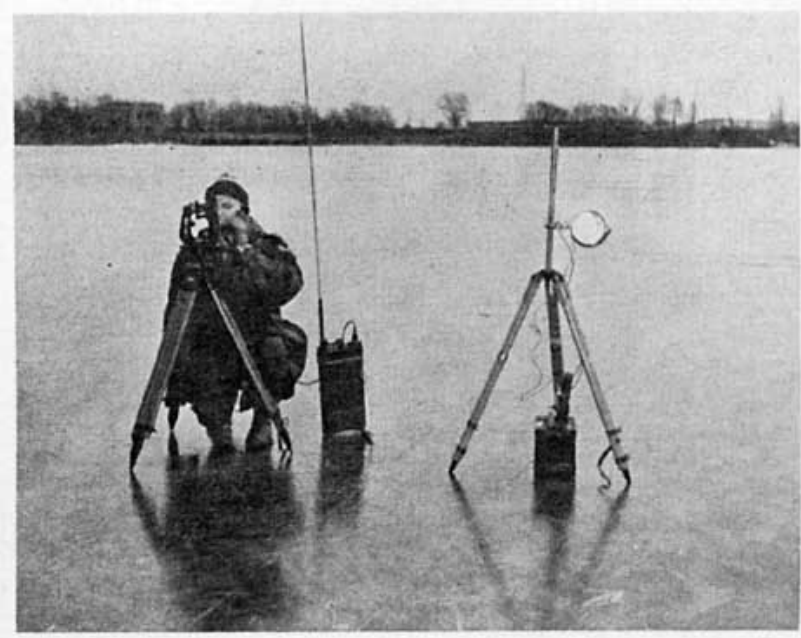

FIG. 2. Chart observer, telescope, D. C. light source, and communications system.

broken rings with arbitrary orientations were moved into position until the observer, in the judgment of the chart operator, could no longer discern the correct orientation. The recorded limit of his resolution was the slot size of the smallest broken ring whose orientation could be correctly identified. The exact times of the determinations were noted in order to be able to relate the resolution limits to corresponding measurements of scintillation and meteorological parameters.

\section{Results}

Visual resolution and the temperature profile. Bellaire and Elder ${ }^{9}$ showed in 1960 that except for adiabatic and nearly adiabatic conditions, temperature fluctuations in turbulent flow are responsible for scintillation and shimmer and the resulting deterioration in visual resolution. Since the temperature deviation from the mean will be greater for greater average vertical potential temperature gradients for a given vertical displacement, it follows that in turbulent flow scintillation and, therefore, visual resolution should depend directly on the mean vertical potential temperature gradient (Portman et al., 1962). Resolution should thus be optimum during a neutral or adiabatic temperature profile regardless of other meteorological or surface conditions.

A total of 126 observations of resolution limits were made during nighttime inversion conditions over snow. The dependence of smallest discernible slot sizes on the temperature difference between heights of 4 and $0.5 \mathrm{~m}$ is shown in Fig. 3. Each point is the average of all resolution observations within successive one degree centigrade temperature differences. The number of observations is indicated below each point. The dashed line is a visual estimate of the best fit curve.

\footnotetext{
${ }^{9}$ Bellaire, F. R., and F. C. Elder, op. cit.
}

A systematic deterioration of resolution with inversion magnitude is evident. Al temperature differences less than $1 \mathrm{C}$ the orientatioris of slot sizes which averaged about 0.34 inch could be detected, but for differences between $9 \mathrm{C}$ and $10 \mathrm{C}$ the average smallest discernible slot size increased to alsout 0.76 inches. The data were not categorized accordirg to turbulence characteristics, pressure, cloudiness, or absolute temperature, so each point represents ar average for a large range of these conditions.

Visual resolution and wind and cloudiness. Since unique combinations of sky conditions and wind speeds exert a pronounced influence on vertical temperature gradients, the same observations of resolution limits were categorized according to the amount of cloudiness and related to wind speed. The value of these parameters is that they are readily avcilable from standard weather station observations in contrast to the temperature profile, which requires de tailed measurements. The results obtained over snow at night are shown in Fig. 4. Relationships of resolution to the 2-m wind speed are shown for two general sky conditions: 1) clear or scattered and 2) broken or overcast. The dashed line is a visual estimate of the hest fit curve for the clear or scattered sky condition. The number of observations is indicated below each point.

For a clear or scattered sky condition, the deterioration in resolution is evident by the increase in the smallest discernible slot size frorn about 0.38 to 0.72 inch as the wind speed increases to about $5.0 \mathrm{mph}$. The most pronounced inversions existed below this speed. An increase in wind speed from nearly calm to about $5 \mathrm{mph}$ caused wind shear effects and vertical motions to increase. The magnitude of temiperature fluctuations increased correspondingly, shimmer increased, and visual resolution deteriorated. However, the same wind shear effects above this speed tended to decrease the temperature gradient through mixing action, even though vertical motions continued to increase. As a result, the magnitude of temperiture fluctuations decreased, shimmer decreased, and the improvement in visual resolution is evident by the decrease in the smallest discernible slot size from about 0.72 to 0.5 inch. Presumably, resolution woruld continue to improve as wind speed increased until the absolute resolution limit of the observer and telescope system (about 0.2 inch for the $543 \mathrm{~m}$ optical pa1.h) were reached.

For broken or overcast sky conditions, indicated in the figure by triangular points, fewer observations were available, but resolution in all :such cases was much better and nearly independent of wind speed. The average discernible slot size for these conditions was 0.3 inch. Such behavior reflects the smaller initial temperature gradients with these sky conditions. Although vertical motions increasec. with wind speed, the magnitude of temperature fluctuations remained small, 


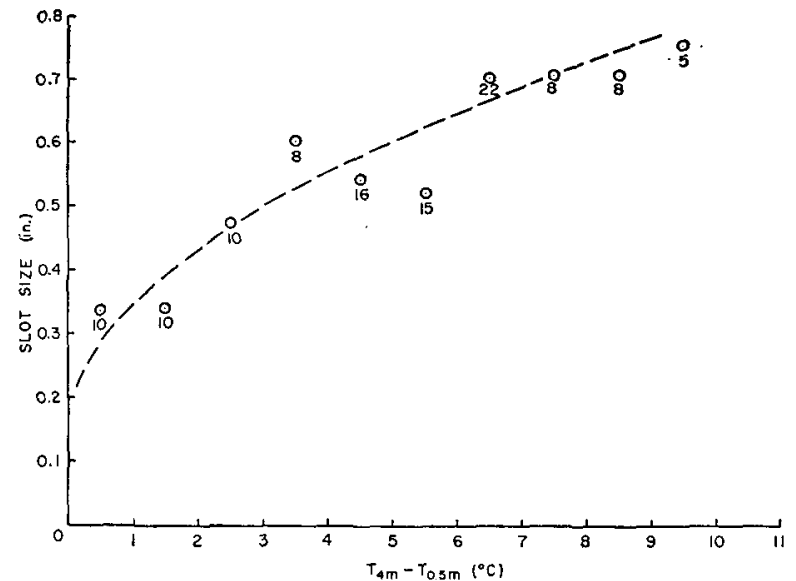

Fig. 3. Visual resolution limits vs. vertical temperature difference.

shimmer remained low, and visual resolution remained quite good.

The relatively few observations of resolution made over snow in daylight correspond in a general way with those obtained at night. However, average resolution conditions were much better in daytime than at night. A relatively small slot size of 0.24 inch was nearly always discernible. Such conditions would be expected from the fact that all temperature differences measured for the daytime observation periods were relatively small.

The observations on which both relationships in Fig. 5 are based were obtained at subfreezing temperatures and during inversions which formed due to net radiation losses from the snow surface. As a result, the average validity of these relationships and the statements regarding daytime resolution are limited by possible advection effects. For example, over a snow surface, the advection of air which is well above freezing would produce an advection inversion. Intense shimmer and poor resolution could then exist at quite high wind speeds and would be nearly independent of sky condition or time of day. Also, the advection of extremely colder air at low wind speeds on a clear night could conceivably suppress the formation of a pronounced inversion and thereby inhibit the intensity of shimmer. This could occur if the average air temperature in the lowest few meters decreased as fast due to the influx of colder air as the snow surface temperature decreased due to net radiation losses.

Visual resolution and scintillation. To illustrate the compatibility of the studies of optical scintillation and visual resolution, the dependence of resolution limits on per cent modulation is shown in Fig. 5. Each point is the average of the slot sizes which correspond to average values of scintillation per cent modulation $(\mathrm{Pm})$ in Pm categories of 1-10, 11-20, 21-30, etc. Standard deviations of slot size and the number of observations which comprise each average are shown.

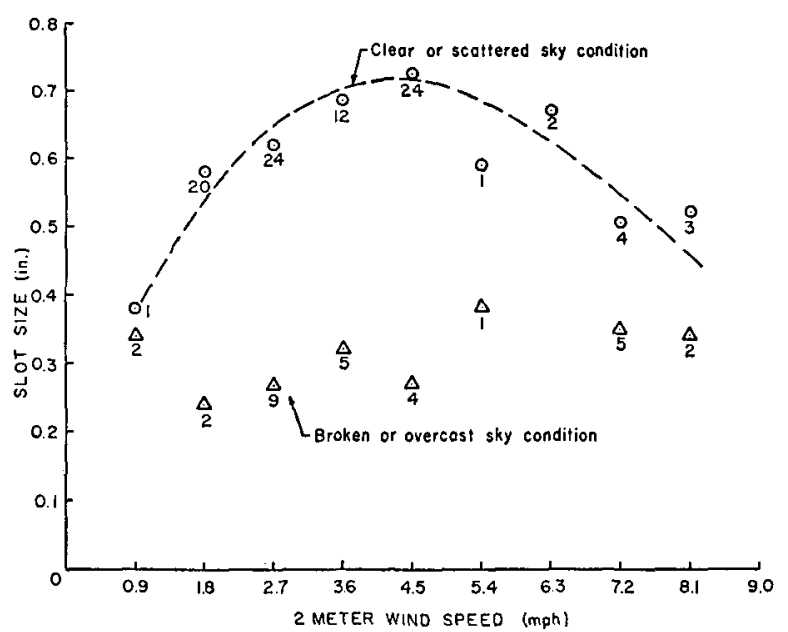

Fig. 4. Visual resolution limits vs. 2-m wind speed for (1) clear or scattered and (2) broken or overcast sky conditions.

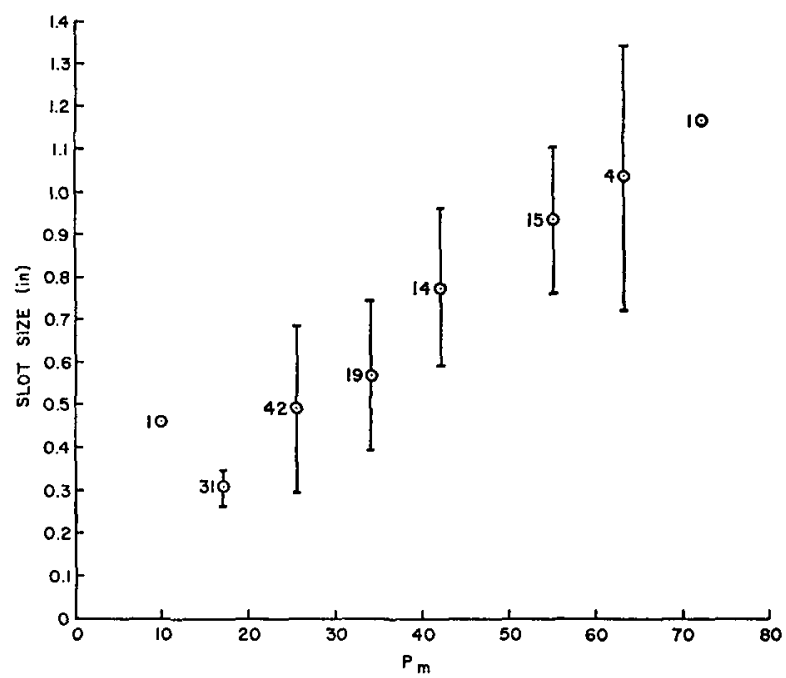

FIG. 5. Visual resolution limits vs. scintillation per cent modulation.

It is apparent that visual resolution deteriorates as scintillation increases in intensity. Average values of resolution limits which contain more than one observation range from 0.31 inch to 1.17 inches and the corresponding values of $\mathrm{Pm}$ range from 17 to 63 .

The scatter of individual observations, indicated by the standard deviations, may be explained by a number of factors. Perhaps one of the most important was the high variability of scintillation during conditions of poor resolution. It was particularly pronounced during periods of extremely stable thermal stratification and very light wind. The variability of scintillation influenced the resolution determinations because of the time required to establish the limit of resolution. The final slot size accepted as the resolution limit in such cases may not have been the most accurate measure of 
the average resolution conditions during the corresponding two-minute average of $\mathrm{Pm}$. Also, during conditions of extremely low scintillation and excellent resolution the smallest possible discernible slot size was determined by the observer's ocular abilities, the magnifying power of the telescope, the illumination of the resolution chart, and other factors which are less obvious but possibly as important.

\section{Summary and conclusions}

From empirical relationships between micrometeorological parameters and visual resolution, it appears possible to estimate visual resolution conditions from standard meteorological information for stable thermal stratification over snow. In turbulent flow, resolution deteriorated with an increase in the average vertical temperature gradient. Resolution was best in the absence of thermal stratification and poorest in very stable thermal stratification with light winds. With a clear or scattered sky condition, resolution deteriorated as wind speed increased up to about $5 \mathrm{mph}$. Above this speed the inverse relationship between wind speed and vertical temperature gradients caused a gradual improvement in resolution. With broken or overcast sky conditions good resolution predominated at all wind speeds because of the absence of pronounced thermal stratification. Resolution deteriorated systematically as scintillation increased in intensity.

The fact that the conclusions refer to observations made at night when vision was necessarily restricted does not limit the significance of the findings. The analysis sought to relate resolution to meteorological conditions independent of time of day. However, since inversions are common over higher latitude snow surfaces even during daytime, the :esults should be particularly useful for cold region of erations.

Acknozoledgments. The authol extends his sincere thanks to members of the staff of the meteorological laboratories for their contributions to this paper. In particular, thanks are extended to Floyd C. Elder for his valuable contributions to both the measurement and analysis phases of the investigation and to Donald $\mathrm{J}$. Portman for his consistent interest and constructive advice in supervising the work.

\section{REFERENCIS}

Eliison, M. A., 1954: Location, size and speed of refractional irregularities causing scintillation. Quart. J. R. meteor. Soc., 80, 246-248.

Fritz, N. A., 1928: Essai de determiration experimentale de la progression a donner a l'echelle c'acuite visuelle. Bull. Soc. Belge. Opthal., 60, 58-66.

Gurvich, A. S., V. I. Tatarskii and L. J'. Cvang, 1958: An experimental research on the statistical characteristics of scintillation of a light source at ground level. (Trans. by E. R. Hope) Dok. Acad. Nauk, SSSR, 123, 655-658.

Middleton, W. E. K., 1952: Vision though the atmosphere. Univ. of Toronto Press, p. 80.

Portman, D. J., F. C. Elder, E. Ryznar and V. E. Noble, 1962: Some optical properties of turbulınce in stratified flow near the ground. $J$. geophys. Res., 67, 3223-3235.

Siedentopf, von H., and F. Wisshak, 1948: Die szintillation der strahlung terrestrischer lichtquellen und ihr gang mit der tageszeit. Optik, 3, 430-433.

Tatarski, V. I., A. S. Gurvich, M. A. Kallistratova and L. V. Terenteva, 1958: The influence of meteorological conditions on the intensity of light scintillation near the earth's surface. J. Soviet Astron., 2, 578-581. (Translated by American Institute of Physics Advisory Boarc of Russian Translations) 